\title{
DEVELOPMENT AND VALIDATION OF TETRACYCLINE HYDROCHLORIDE ASSAY PROCEDURE BY SPECTROPHOTOMETRY IN COMPOUNDED OINTMENT
}

\author{
Ivan Bezruk, Valentin Vrakin, Lesia Savchenko, Anna Materiienko, Victoriya Georgiyants \\ National University of Pharmacy, Kharkiv, Ukraine
}

\begin{abstract}
AIM: Tetracycline hydrochloride is one of the most popular antibiotics, which are used in the manufacturing of finished pharmaceutical products and compounded medicines. The aim of our work is development and validation of the assay method for tetracycline hydrochloride determination in the combined compounded ointment.
\end{abstract}

MATERIALS AND METHODS: The assay is proposed to be carried out by spectrophotometric method.

RESULTS AND CONCLUSIONS: A spectrophotometric method for tetracycline hydrochloride determination in compounded ointment was developed. For this method the following validation characteristics were studied: stability, selectivity, repeatability, precision, accuracy, reproducibility. We found that all metrological characteristics are not higher than the validation criteria. Stability of test solutions was observed for $\mathbf{6 0}$ minutes, which allows using this method for tetracycline hydrochloride quantitative determination in studied ointment.

Keywords: tetracycline hydrochloride, compounded preparation, spectrophotometry, validation

\section{INTRODUCTION}

Extemporaneous medicines have some benefits over manufacturing drugs because they allow using a more streamline approach to each patient. Drugs prepared in the pharmacy offer a more individual approach to disease treatment, namely they allow to select doses of drug substance depending on the patient condition $(1,2)$. Also compounded preparations provides the opportunity to change the substance composition taking into account patient allergies $(3,4)$. These positive aspects are one of the main rea-

\footnotetext{
Address for correspondence:

Anna Materiienko

National University of Pharmacy

53 Pushkinska Str.

61002 Kharkiv, Ukraine

e-mail:anna.materienko@gmail.com
}

Received: March 20, 2017

Accepted: June 13, 2017 sons, why we are observing the rebirth and expansion of pharmaceutical technology in the pharmacies of Ukraine.

Such rapid growth leads to the necessity of developing new methods for qualitative and quantitative control of compounded dosage forms, which allow the determining of the drug composition more accurately and quickly to ensure the provision of the highest quality of pharmaceutical care.

Tetracycline hydrochloride is one of the most often used antibiotics. It is the founder of one of the biggest group of antibacterial drugs. It has a bacteriostatic effect on a wide range of pathogens and is used in the treatment of pneumonia, dysentery, gonorrhea and the other infectious diseases $(5,6)$.

Tetracycline hydrochloride is most often produced in the form tablets, capsules and suspensions, and rarely applied as an injection. It is frequently used externally as an ointment for treatment of burns, wounds and eye diseases. The manufactured 
tetracycline ointment is often used as basis for a large number of compounded dosage forms, which have combined compositions and allow the expansion of the pharmacological effects of tetracycline hydrochloride by adding ingredients, which have another effect (6).

Pharmacopoeias suggest assay of tetracycline hydrochloride by chromatographic and biological methods $(7,8)$. But neither of these methods may be used in pharmacy conditions, because they need to have special expensive equipment, reagents and trained personnel for substance determination.

In addition to quality control of compounded preparations during the manufacturing and selling at the pharmacy, a development of accurate methods for ingredients assaying is also necessary for studying the drug stability.

The aim of our work was development and validation of the tetracycline hydrochloride assay method in combined compounded ointment with the following composition:

\begin{tabular}{|l|l|}
\hline Rp.: & Streptocidi 1.0 \\
& Novocaini 0.5 \\
& Sulfuris 0.5 \\
& Ung. Tetracyclini 3\% - 15.0 \\
& M. D. S. \\
\hline
\end{tabular}

\section{MATERIALS AND METHODS}

Analytical equipment composed of the following appliances: Evolution 60S (Thermo, USA) spectrophotometer; AXIS ANG200 balances (Poland); pH-150 MI potentiometer (Ukraine) and Specord 200 (Germany), was used for the analysis. The experimental studies were conducted using class A measuring glassware and excipients meeting the requirements of the State Pharmacopoeia of Ukraine (SPhU) (7), which is harmonized with the European ones (8).

Preparation of the dosage form test solution: $0.5 \mathrm{~g}$ of ointment (accurate weight) was placed in a chemical glass, $5 \mathrm{ml}$ of hexane $\mathrm{R}$ was added and intensively stirred to dissolve the ointment base. The received solution was placed into a separating funnel. The glass was washed with $3 \mathrm{ml}$ of hexane R, also placing this in a separating funnel. Extraction of tetracycline hydrochloride was carried out by $10 \mathrm{ml}$ portions of phosphate buffer solution $(\mathrm{pH} 4.5)$ with placing of the extract into a $100 \mathrm{ml}$ volumetric flask each time. The last two times extraction was carried out by $5 \mathrm{ml}$ portions of $0.1 \mathrm{M} \mathrm{HCl}$ solution. The obtained solution was diluted to the $100 \mathrm{ml}$ mark with phosphate buffer solution ( $\mathrm{pH} 4.5)$ and mixed. The solution was filtered, $5.0 \mathrm{ml}$ of it was transferred into a $25.0 \mathrm{ml}$ volumetric flask and diluted to the mark by phosphate buffer solution with $\mathrm{pH} 4.5$.

Preparation of the standard solution: $0.07 \mathrm{~g}$ of tetracycline hydrochloride reference standard (accurate weight) was placed into a $100 \mathrm{ml}$ volumetric flask, dissolved in $30 \mathrm{ml}$ of phosphate buffer solution with $\mathrm{pH} 4.5,5 \mathrm{ml}$ of $0.1 \mathrm{M} \mathrm{HCl}$ was added, stirred and diluted to the $100 \mathrm{ml}$ mark with phosphate buffer solution ( $\mathrm{pH} 4.5$ ). After this, $2.0 \mathrm{ml}$ of obtained solution was transferred into a $50 \mathrm{ml}$ volumetric flask and diluted to the mark with the same solvent.

\section{RESULTS AND DISCUSSION}

The UV and visible spectrophotometry method was chosen as an assay method. This method allows the determination of the content of the organic compounds accurately and inexpensively. The use of a titrimetric method for analysis in this case is impossible, because the prescription is multicomponent and other components interfere with the analysis results.

At the first stage of the spectrophotometric procedure development, we studied the nature of tetracycline hydrochloride spectra in different solvents, such as $0.1 \mathrm{M} \mathrm{HCl}, 0.1 \mathrm{M} \mathrm{NaOH}$, phosphate buffered solution ( $\mathrm{pH} 4.5$ ), water $\mathrm{R}$, ethanol $\mathrm{R}$ and methanol $\mathrm{R}$.

Tetracycline undergoes reversible epimerisation in solution to the less active 4-epitetracycline; the degree of epimerisation is dependent on $\mathrm{pH}$, and is greatest at a $\mathrm{pH}$ of about 3 , with conversion of some $55 \%$ to the epimer at equilibrium. The important reactions with the $\mathrm{pH}$-dependent are formation of anhydrotetracycline at $\mathrm{pH} 2$ or less, and oxidation to isotetracycline at alkaline solution (9).

The obtained results showed that tetracycline hydrochloride was unstable in alkaline medium. The absorption spectra of tetracycline hydrochloride in other solvents have broad absorption band in the UV area with a maximum at $269 \mathrm{~nm}$ (ethanol, methanol, $\mathrm{HCl}$ ) or $277-279 \mathrm{~nm}$ (water and phosphate buffered solution), which is nonspecific and cannot be used for tetracycline hydrochloride assay in the combined 
Ivan Bezruk, Valentin Vrakin, Lesia Savchenko et al.

dosage forms by direct spectrophotometry method. Also absorption spectrum of tetracycline hydrochloride has a maximum in the visible area at $357-358 \mathrm{~nm}$ (for water solutions) or $362-363 \mathrm{~nm}$ (for alcoholic solutions), which might be used for its assay in the studied ointment (Fig.1).

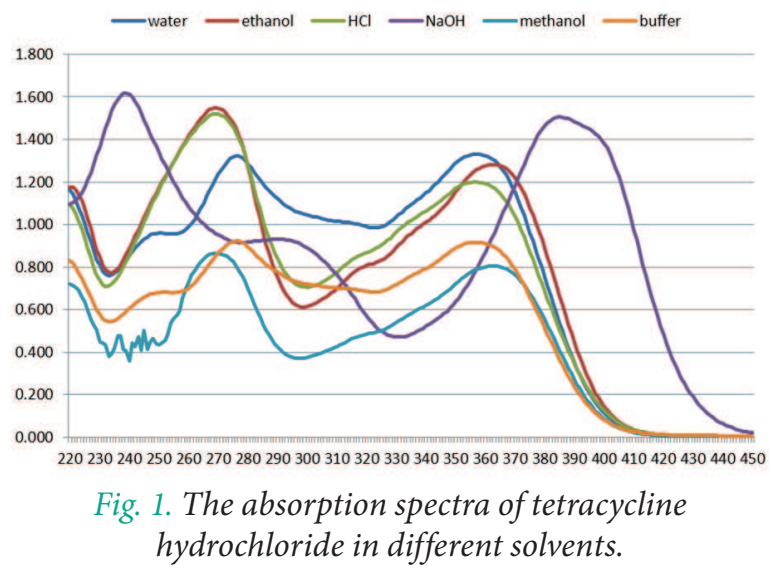

The next step in the assay method development was sample preparation, during which the optimal way for tetracycline hydrochloride extraction from the ointment base and dosage form must be established.

Solutions of tetracycline in $0.1 \mathrm{M} \mathrm{HCl}$ and $0.1 \mathrm{M}$ $\mathrm{NaOH}$ are unstable. When using water for extraction of tetracycline hydrochloride from the ointment, it undergoes partial hydrolysis to form the tetracycline base, which is insoluble in water, that is why it was decided to use methanol $\mathrm{R}$ for the extraction. Upon further study of this extraction method, we found that part of the ointment base was soluble in methanol and affected negatively the results of the assaying, making them higher. According to the literature data, extraction of tetracycline hydrochloride can be carried out with phosphate buffer solution, but direct extraction from the ointment base did not show positive results.

For the further development of the sample preparation method, we decided to dissolve the ointment sample in minimum quantity of organic solvent (hexane $\mathrm{R}$ ) with the tetracycline hydrochloride extracting by phosphate buffer solution ( $\mathrm{pH}$ 4.5). During the stability study of tetracycline hydrochloride solutions in the different solvents and extraction completeness, phosphate buffer solution ( $\mathrm{pH} 4.5$ ) showed the highest result. For this reason we chose it for the sample preparation.

Thus, we experimentally established, that the most optimal way for the sample preparation of this ointment was dissolution of accurate ointment sample in a minimum amount of hexane $\mathrm{R}$ with the further extraction of tetracycline hydrochloride by phosphate buffer solution ( $\mathrm{pH} 4.5$ ).

Since the studied ointment is multicomponent, we had to prove that all other components did not affect the tetracycline hydrochloride absorption spectrum. We studied absorption spectra of substances and their mixture. We prepared solutions of sulfanilamide, procaine hydrochloride and tetracycline hydrochloride in concentration near to the prescribed in the ointment. We used the phosphate buffer solution $(\mathrm{pH} 4.5)$ as a solvent.

Results of studies have shown that procaine hydrochloride and sulfanilamide did not affect at the tetracycline hydrochloride maximum absorption at wavelength $357 \mathrm{~nm}$. This allows the use of direct spectrophotometry for tetracycline hydrochloride assay in this ointment (Fig. 2).

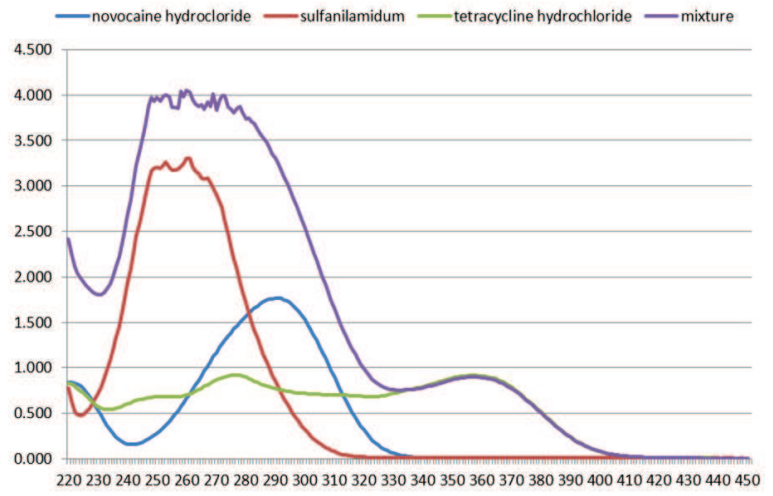

Fig. 2. The absorption spectra of sulfanilamide, procaine hydrochloride, tetracycline hydrochloride and their mixture in the phosphate buffer solution ( $\mathrm{pH} 4.5$ ).

One of the main requirements, which allows using spectrophotometric methods for substance assaying, is that it follows the Bouguer-Lambert-Beer law.

To check whether the substance solution light absorption follows the Bouguer-Lambert-Beer law, we need to draw graph dependence of the absorbance 
Development and Validation of Tetracycline Hydrochloride Assay Procedure by Spectrophotometry in Compounded Ointment

Table 1. Stability studies of analytical method in time

\begin{tabular}{|c|c|c|c|c|c|c|c|c|c|}
\hline \multirow{2}{*}{ Solution } & \multicolumn{5}{|c|}{ Study time, t, min. } & \multirow{2}{*}{ Mean } & \multirow{2}{*}{$\mathbf{R S D}_{t}, \%$} & \multirow{2}{*}{$\Delta_{t}, \%$} & \multirow{2}{*}{$\max \delta, \%$} \\
\hline & $\mathbf{0}$ & 15 & 30 & 45 & 60 & & & & \\
\hline A & 0.859 & 0.858 & 0.858 & 0.858 & 0.857 & 0.858 & 0.0589 & 0.13 & 1.02 \\
\hline $\mathrm{A}_{0}$ & 0.957 & 0.956 & 0.957 & 0.956 & 0.956 & 0.956 & 0.0529 & 0.11 & 1.02 \\
\hline
\end{tabular}

of the solution concentration. The light absorption of the solution obeys the Bouguer-Lambert-Beer law within the concentration, in which the constructed calibration graph appears as a straight line.

After a series of experimental studies we established that the tetracycline hydrochloride solution obeys this law within concentrations from 0.5 to $3.15^{\star} 10^{-3} \mathrm{mg} / \mathrm{ml}$, the specific absorbance is $342.5 \pm 8.5$.

During the research, the suitable technique for tetracycline hydrochloride assay method in the studied ointment was offered.

Validation of the method was carried out in accordance with the SPhU requirements and the standard procedure for validation of the methods for quantitative determination of compounded medicines in pharmacies and quality control laboratories $(2,3)$. SPhU is harmonized with the requirements of EP that allow using this method all around the Europe. During the study the main validation characteristics such as stability, selectivity, repeatability, precision, accuracy and reproducibility were considered.

To assess the sample preparation error of test and standard solutions, theoretical uncertainty values of analytical operations were calculated $(4,5)$. The total uncertainty of the sample preparation for the developed method was: $\Delta_{\mathrm{SP}}=1.00 \%$.

During the validation of tetracycline hydrochloride assay method, some of the validation parameters were considered at first: the stability of test solution in time, linearity, repeatability and accuracy. Researches were conducted under the same conditions: at the same day, on the same device and by the same analyst.

The stability testing of solution was carried out within 60 minutes for both the standard and the model solutions ( $A$ and $\mathrm{A}_{0}$ - mean value of the absorbance of three results for model and standard solutions respectively).

The table above shows that the analytical solution is stable for 60 minutes, which allows using the developed method for the analysis.
To confirm the selectivity of the method, we calculated the systematic error by applying the solvent and reagents to placebo. We measured the absorbance of blank and standard solutions.

Ointment without tetracycline hydrochloride was prepared as placebo. Blank solution (A blank) was prepared by the same method as the test solution. Absorbance measurements of blank (A blank) and standard (A st) solutions were conducted in parallel. We obtained the following results: A blank $=0.006 ;$ A st $=0.974$, which confirm the absence of significant influence on the measurement results.

The study of linearity was carried out by the standardized procedure by measuring the absorbance of 9 model solutions, as recommended by $\mathrm{SPhU}$, for assay of active pharmaceutical ingredients in dosage forms from $80 \%$ to $120 \%$ in increments of 5\%. The results are presented in Table 3 and Fig. 3.

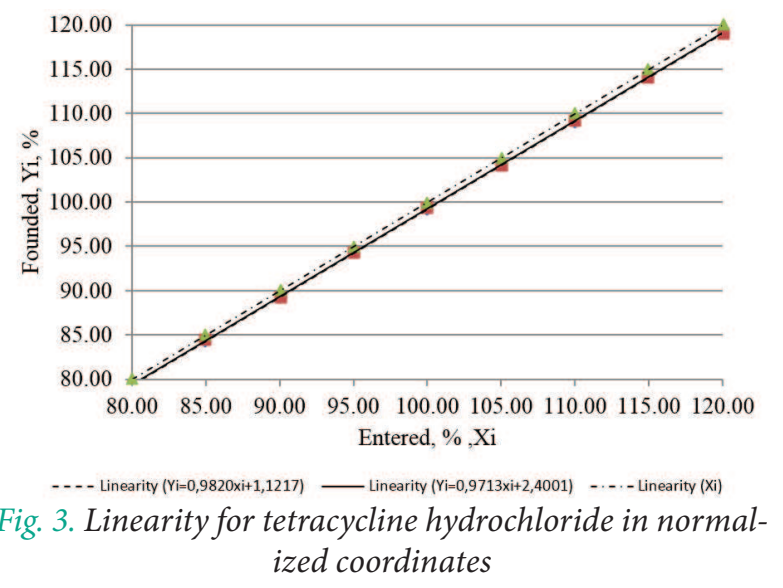

We calculated the ratio of mean absorbance values for each of the solutions to the mean absorbance of the reference solution, getting the magnitude of

$$
X_{i}=\frac{C_{i}}{C_{s t}} \cdot 100 \%, \quad Y_{i}=\frac{A_{i}}{A_{s t}} \cdot 100 \% \quad . \quad \mathrm{We}
$$

worked in the normalized coordinates by showing concentration and the analytical signal as a percentage of the nominal values. We found also the value of 


\begin{tabular}{|c|c|c|}
\hline \multirow{2}{*}{ Characteristic } & \multicolumn{2}{|c|}{ Value } \\
\hline & Laboratory № 1 & Laboratory №2 \\
\hline \multicolumn{3}{|l|}{ Repeatability and accuracy } \\
\hline Mean, Z,\% & 99.19 & 99.25 \\
\hline Relative standard deviation, $\mathrm{S}_{z} \%$ & 0.5066 & 0.1837 \\
\hline Relative confidence interval, $\Delta_{z}, \%$ & 0.9421 & 0.3416 \\
\hline Critical value for repeatability of results, $\Delta_{\mathrm{As}} \%$ & 3.20 & 3.20 \\
\hline Systematic error, $\delta$ & 0.81 & 0.75 \\
\hline Statistically acceptable value, $\delta, \%$ & 0.31 & 0.11 \\
\hline Practically acceptable value, $\delta, \%$ & 1.02 & 1.02 \\
\hline \multicolumn{3}{|l|}{ Linearity } \\
\hline The slope of the linear dependence, $b$ & 0.9917 & 0.9909 \\
\hline $\mathrm{S}_{\mathrm{b}}$ & 0.0142 & 0.0050 \\
\hline Free member of the linear dependence, a & 0.0170 & 0.1572 \\
\hline The critical value for free member, a & 2.7206 & 0.9496 \\
\hline $\mathrm{S}_{\mathrm{a}}$ & 1.4360 & 0.5012 \\
\hline The correlation coefficient, $r$ & 0.9993 & 0.9999 \\
\hline Criterion of the linear correlation coefficient, $\mathrm{R}_{c}$ & 0.9992 & 0.9999 \\
\hline
\end{tabular}

$Z_{i}=\frac{Y_{i}}{X_{i}} \cdot 100 \%$, which is the concentration found as a percentage of the entered.

Repeatability and accuracy were determined by calculating the mean values, the relative standard deviation, relative confidence interval, the critical value for repeatability of results, and systematic error (Table 2).

Precision was assessed based on the analysis of 9 model solutions of various series, that was conducted in two various days and different analysts in the same laboratory. To prepare two different series, various ointments were made. For preparation of these series of dilutions, different laboratory measuring glassware was used. During sample preparation and conducting method fluctuations of temperature, humidity, barometric pressure and other factors inside the laboratory, which affect the analysis, were possible.

The method is correct, because $\Delta \mathrm{Z}$ complies with the requirements: $\Delta \mathrm{Z} \% \leq \max \Delta_{\mathrm{As}}=0.78 \%$. The method has no significant error.

To investigate the reproducibility of this method in other laboratories, measuring of absorbance of
Table 3. Results of spectrophotometry method reproducibility study on model mixture

\begin{tabular}{|c|c|c|}
\hline \multirow{2}{*}{ № of the model solution } & \multicolumn{2}{|c|}{ Values $\mathrm{Z}_{\mathrm{i}}$} \\
\hline & Lab.№ 1 & Lab.№2 \\
\hline 1 & 99.68 & 99,49 \\
\hline 2 & 98.99 & 99,36 \\
\hline 3 & 98.38 & 99,37 \\
\hline 4 & 99.33 & 99,02 \\
\hline 5 & 98.95 & 99,16 \\
\hline 6 & 99.42 & 98,98 \\
\hline 7 & 99.98 & 99,15 \\
\hline 8 & 99.36 & 99,31 \\
\hline 9 & 98.60 & 99,43 \\
\hline Mean, $Z_{i}, \%$ & 99.19 & 99,25 \\
\hline Combined mean, $\mathrm{Z}_{\text {intra }} \%$ & \multicolumn{2}{|c|}{99.22} \\
\hline $\begin{array}{l}\text { Relative standard } \\
\text { deviation, } S_{\text {intra }} \%\end{array}$ & 0.51 & 0.18 \\
\hline $\begin{array}{l}\text { Combined relative stan- } \\
\text { dard deviation, } \mathrm{SD}_{\text {intra }} \%\end{array}$ & \multicolumn{2}{|c|}{0.38} \\
\hline Interlaboratory bias, $\delta, \%$ & \multicolumn{2}{|c|}{0.78} \\
\hline $\begin{array}{l}\text { Confidence interval of a } \\
\text { single value } \Delta_{x, r} \%\end{array}$ & \multicolumn{2}{|c|}{ \pm 0.67} \\
\hline $\begin{array}{l}\text { Confidence interval of the } \\
\text { mean value } \Delta_{x, y} \%\end{array}$ & \multicolumn{2}{|c|}{ \pm 0.31} \\
\hline
\end{tabular}


the same series model ointment with tetracycline hydrochloride solutions on different equipment, on different days and in two different laboratories was carried out $(1,7)$.

The obtained results (shown in Table 3) are a comparison of two different statistical deviations measurements, which were conducted in different laboratories, using different equipment. Data show that the proposed method can be reproduced in other laboratories. It is characterized by relative confidence interval $100 \pm 0.67 \%$ with $95 \%$ probability. The value of $\Delta \mathrm{x}, \mathrm{r}, \%=0.67 \leq 3.2$.

\section{CONCLUSIONS}

The method for tetracycline hydrochloride assay in the compounded ointment was developed and validated. It has been established that the metrological characteristics of such method validation parameters as stability, selectivity, repeatability, precision, accuracy, reproducibility do not exceed validation criteria. Stability of the test samples was observed within 60 minutes, which allows using this method for analysis of the compounded dosage form. The method can be reproduced in laboratory conditions, with a confidence interval of $95 \%$ and a single value deviation of $100 \pm 0.67 \%$.

\section{REFERENCES}

1. Kristina SA, Wiedyaningsih C, Widyakusuma $\mathrm{NN}$, Aditama H. Extemporaneous compounding practice by pharmacists: a systematic review. Int $\mathrm{J}$ Pharm Pharm Sci. 2008; 9(2):42-6.

2. Buurma H, de Smet P, van den Hoff OP, Sysling H, Storimans M, Egberts CG. Frequency, nature and determinants of pharmacy compounded medicines in Dutch community pharmacies. Pharm World Sci. 2003; 25 (6):280-7. doi:10.1023/ B:PHAR.0000006521.41736.db

3. Feldschuh M. Compounding in community pharmacy. Aust Prescr. 2008; 31(2):30-1. doi: 10.18773/ austprescr.2008.016

4. Falconer JR, Steadman KJ. Extemporaneously compounded medicines. Aust Prescr. 2017; 40(1): 5-8. doi: 10.18773/austprescr.2017.001

5. Chopra I, Roberts M. Tetracycline antibiotics: mode of action, applications, molecular biology, and epidemiology of bacterial resistance. Microbiol Mol Biol Rev. 2001; 65(2):232-60. doi: 10.1128/ MMBR.65.2.232-260.2001
6. Roberts MC. Tetracycline Therapy: Update. Clin Infect Dis. 2003; 36(4):462-7. doi: 10.1086/367622

7. State Pharmacopoeia of Ukraine: in 3 vol. // SE "Ukrainian scientific pharmacopoeial center of medicines quality". - 2nd ed. -Kharkiv: SE "Ukrainian scientific pharmacopoeial center of medicines quality", 2015. -. Vol. 1. - 1128 p. (in Ukrainian).

8. European Pharmacopoeia. Available from: http:// online6.edqm.eu/ep802/.

9. Mohammed-Ali MAJ. Stability study of tetracycline drug in acidic and alkaline solutions by colorimetric method. J Chem Pharm Res. 2012; 4(3): 1319-26.

10. Hubert $P$, Nguyen-Huu JJ, Boulanger $B$, Chapuzet E, Chiap P, Cohen N et al. Harmonization of strategies for the validation of quantitative analytical procedures: a SFSTP proposal-part I. J Pharm Biomed Anal. 2004; 36 (3):579-86. doi: 10.1016/j. jpba.2004.07.027

11. Crowther JB. Validation of pharmaceutical test methods. In: Ahuja S, Scypinski S, editors. Handbook of Modern Pharmaceutical Analysis. San Diego, CA: Academic Press; 2001. pp. 415-43.

12. Behera S, Ghanty S, Ahmad F et al. UV-visible spectrophotometric method development and validation of assay of paracetamol tablet formulation. J Anal Bioanal Techniques. 2012; 3(6):151-7. doi: 10.4172/2155-9872.1000151

13. Sawant R, Bhangale L, Joshi R. et al. Validated spectrophotometric methods for simultaneous estimation of Paracetamol, Domperidone and Tramadol $\mathrm{HCl}$ in pure and tablet dosage form. J Chem Metrol. 2010; 4(1): 21. 